\title{
Male Reproductive System Alteration
}

National Cancer Institute

\section{Source}

National Cancer Institute. Male Reproductive System Alteration. NCI Thesaurus. Code C40934.

Male Reproductive System Alteration involves a qualitative change in the existing activity of the male reproductive organs, which include the penis, scrotum, urethra, testis, epididymis, ductus deferens, seminal vesicle, ejaculatory duct, prostate, and bulbourethral gland. 